\title{
Dent disease type 2
}

INSERM

\section{Source}

INSERM. (1999). Orphanet: an online rare disease and orphan drug data base. Dent disease type 2. ORPHA:93623

Dent disease type 2 is a type of Dent disease in which patients have the manifestations of Dent disease type 1 associated with extra-renal features. 